Results: 338.343 RA hospital admissions were detected in the study period, being $81.468(24,07 \%)$ due to infections. The main clinical-demographic characteristics are shown in table 1 :

\begin{tabular}{lccccccc}
\hline & Women & Men & Total & $\begin{array}{c}\text { 1999- } \\
\text { 2002 }\end{array}$ & $\begin{array}{c}\text { 2003- } \\
\text { 2006 }\end{array}$ & $\begin{array}{c}\text { 2007- } \\
\text { 2010 }\end{array}$ & $\begin{array}{c}\text { 2010- } \\
\text { 2015 }\end{array}$ \\
\hline N (\%) & 53528 & 27939 & 81467 & 10518 & 15644 & 21280 & 34025 \\
& $(65.7 \%)$ & $(34.3 \%)$ & $(100)$ & & & & \\
Mean Age (SD) & 71.38 & 70.62 & 71.12 & 68.39 & 69.65 & 71.21 & 72.60 \\
& $(13.3)$ & $(12.47)$ & $(13.02)$ & $(12.73)$ & $(12.93)$ & $(13.12)$ & $(12.89)$ \\
Dead during & 5139 & 2957 & 8096 & ND & ND & ND & ND \\
admission, n (\%) & $(9.6)$ & $(10.5)$ & $(9.93)$ & & & & \\
Mean Charlson & 2.05 & 2.45 & 2.19 & 1.90 & 2.0 & 2.18 & 2.37 \\
Index (SD) & $(1.5)$ & $(1.8)$ & $(1.63)$ & $(1.40)$ & $(1.51)$ & $(1.60)$ & $(1.75)$ \\
Average length & 13.86 & 14.14 & 13.9 & 15.94 & 15.36 & 14.43 & 12.42 \\
of stay (SD) & $(16.3)$ & $(15.5)$ & $(16.1)$ & $(18.84)$ & $(17.23)$ & $(16.77)$ & $(13.93)$ \\
\hline
\end{tabular}

The annual age-adjusted rate of infections increased during the study period, especially in men (fig I). The annual trend of infections age-adjusted increased during the study period $5.29 \%$, women $5.08 \%$ and men $5.92 \%$. For age groups the annual increase was $3.51 \%$ for $20-40$ years, $3, .2 \%$ for $40-60$ years, $4,5 \%$ for $60-80$ years and $9.27 \%$ for $>80$ years

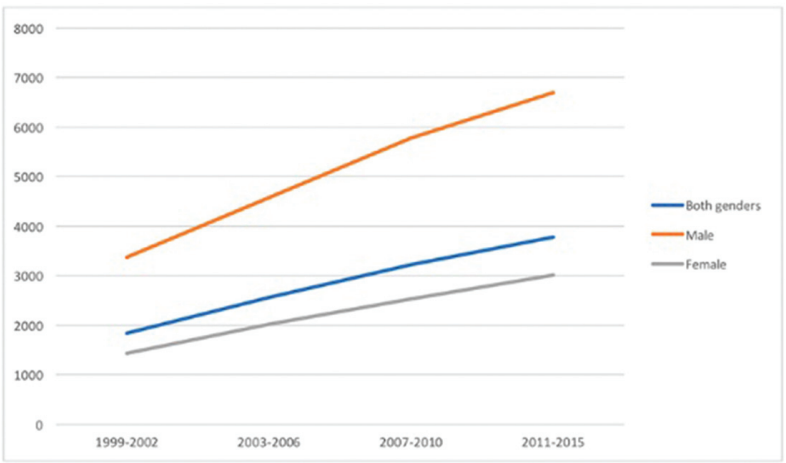

Conclusions: Rate of infection in RA hospitalised patients in Spain has increased during study period. The patients are progressively elderly and has more comorbidities. However the average hospital stay decrease.

Disclosure of Interest: None declared

DOI: 10.1136/annrheumdis-2018-eular.5490

\section{THU0150 IMPACT OF COMORBIDITY BURDEN AND OBESITY ON THE EFFECTIVENESS OF TOCILIZUMAB IN PATIENTS WITH RHEUMATOID ARTHRITIS}

D. Pappas ${ }^{1,2}$, C. Etzel ${ }^{2}$, M. Crabtree ${ }^{2}$, J. Best ${ }^{3}$, S. Zlotnick ${ }^{3}$, J. Kremer ${ }^{4} .{ }^{1}$ Columbia University, New York; ${ }^{2}$ Corrona, LLC, Waltham; ${ }^{3}$ Genentech, Inc, South San Francisco; ${ }^{4}$ Albany Medical College and The Center for Rheumatology, Albany, USA

Background: Few real-world studies have evaluated the impact of comorbidity burden or obesity on the effectiveness of tocilizumab (TCZ) for the improvement of rheumatoid arthritis (RA) disease activity.

Objectives: To compare the effectiveness of TCZ in treating RA in patients with high vs low comorbidity burden and in obese vs nonobese patients in US clinical practice.

Methods: Patients in the Corrona RA registry who initiated TCZ and had followup visits at 6 and 12 months after initiation were included. To assess the impact of comorbidity burden on TCZ effectiveness, outcomes were stratified by patients with low Charlson Comorbidity Index $(\mathrm{CCl}=1)$ vs high $(\mathrm{CCl} \geq 2)$. To assess the impact of obesity, outcomes were stratified by patients with $\mathrm{BMI}<30$ (nonobese) vs $\geq 30$ (obese). The primary outcome was mean change in CDAl at 6 and 12 months. Secondary outcomes were mean change in $\mathrm{HAQ}$, the proportions of patients with change $\geq$ the minimum clinically important difference (MCID) in CDAI and $\mathrm{HAQ}$ and the proportion who achieved low disease activity (LDA; CDAI $\leq 10)$. Baseline demographics, clinical characteristics, disease activity and treatment history in the comorbidity and BMl cohorts were compared separately using standardised differences; characteristics with $\mid$ standardised difference $\mid>0.1$ were identified as covariates for inclusion in adjusted comparisons. Outcomes were compared between cohorts using two-sample $t$-tests or $\chi^{2}$ tests in unadjusted analyses and linear or logistic regression models to adjust for covariates.

Results: Of 770 patients who initiated TCZ and had CCI data available at baseline $(93.8 \%$ treated with intravenous [IV] TCZ and $6.2 \%$ with subcutaneous [SC]
TCZ), 575 (74.7\%) had a low CCI and 195 (25.3\%) a high CCI. Patients with a high $\mathrm{CCl}$ were older (mean [SD] age, 61.5 [12.3] vs 56.9 [13.1] years), were more likely to be obese ( $52.8 \%$ vs $41.7 \%$ ), had a longer disease duration (mean [SD], 12.8 [9.9] vs 11.6 [8.9] years) and had higher mean (SD) baseline CDAI (25.7 [13.4] vs 23.9 [13.9]) and $\mathrm{HAQ}(0.71$ [0.57] vs 0.57 [0.51]) scores than those with a low $\mathrm{CCl}$.

Of the $805 \mathrm{TCZ}$ initiators with BMI data available at baseline $(93.9 \%$ treated with IV TCZ and 6.1\% with SC TCZ), 449 (55.8\%) were not obese and $356(44.2 \%)$ were obese. Obese patients were younger (56.7 [12.0] vs 59.0 [13.7] years), had shorter disease duration (11.4 [8.6] vs 12.6 [9.7] years) and had higher baseline $\operatorname{CDAI}(25.4[14.3]$ vs $23.6[13.4])$ and $\mathrm{HAQ}(0.65[0.53]$ vs 0.57 [0.53]) scores than nonobese patients.

Patients in all cohorts had improvement from baseline in CDAI at 6 and 12 months, with no significant differences between those with a low vs high $\mathrm{CCl}$ or between obese vs nonobese patients (table 1). Secondary outcomes yielded similar results (table 1).

Abstract THU0150 - Table 1. Study Outcomes at 6 and 12 Months in Patient With RA Who Initiated TCZ, Stratified by Comorbidity Burden and Obesity Status

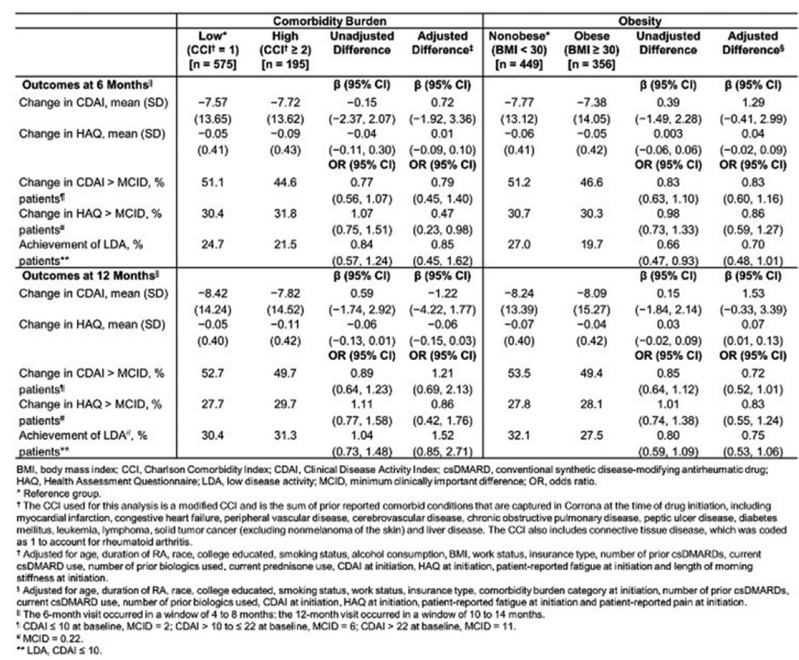

Conclusions: In this real-world analysis, the effectiveness of TCZ for the improvement of RA disease activity was comparable among patients regardless of comorbidity burden or obesity.

Acknowledgements: This study is sponsored by Corrona, LLC. Corrona has been supported through contracted subscriptions in the last 2 years by AbbVie, Amgen, Boehringer Ingelheim, BMS, Celgene, Crescendo, Eli Lilly, Genentech, Gilead, GSK, Horizon Pharma USA, Janssen, Merck, Momenta Pharmaceuticals, Novartis, Pfizer Inc., Roche, UCB and Valeant.

Disclosure of Interest: D. Pappas Grant/research support from: Abbvie, Consultant for: Abbvie, Employee of: Corrona, LLC, C. Etzel Shareholder of: Corrona LLC, Consultant for: Merck, Employee of: Corrona, LLC, M. Crabtree Employee of: Corrona, LLC, J. Best Shareholder of: Genentech, Inc., Employee of: Genen tech, Inc, S. Zlotnick Shareholder of: Genentech, Inc., Employee of: Genentech Inc, J. Kremer Shareholder of: Corrona, LLC, Consultant for: AbbVie, Amgen, Bristol-Myers Squibb, Eli Lilly and Company, Genentech, GlaxoSmithKline Pfizer, Regeneron, Sanofi

DOI: 10.1136/annrheumdis-2018-eular.1740

\section{THU0151 ASSESSMENT OF COMPLIANCE OF RHEUMATOID ARTHRITIS PATIENTS IN COGNITIVE DYSFUNCTION}

E. Grunina ${ }^{1}$, A. Tkachev ${ }^{2} .{ }^{1}$ N. Novgorod State Medical Academy, N. Novgorod; ${ }^{2}$ Milton H. Erickson Institute of West Siberia, Novosibirsk, Russian Federation

Background: Compliance decline may result in a decrease of treatment effectiveness in rheumatoid arthritis. RA patients had global cognitive impairment, which was associated with disease activity and immune changes. ${ }^{1}$ Cognitive dysfunction may have a negative effect on the results of traditional methods of compliance assessment.

Objectives: Our aim was to develop the method of structured and algorithms interview to assess compliance and cognitive functions in patients with rheumatoid arthritis.

Methods: 240 patients fulfilling EULAR 2010 classification criteria for rheumatoid arthritis were examined. Pain in the joints was assessed using a visual analogue scale, the clock-drawing test was used, the structured and algorithms interview with clear determination of at least 3 levels of patient values was performed. ${ }^{2}$ 
Each patient chose the subject of the interview: compliance, pain or side effects of drugs. Subjective values that determine the choice and behaviour of the patient with dichotomy, for example, taking or missing drugs were revealed.

Results: 162 patients chose the theme of the interview concerning of pain, 50 patients chose the theme compliance with drug therapy, 38 patients - side effects of drugs. The criteria of cognitive dysfunction were the following: inability for the patient to determine subjective values influencing the process of decision- making, repeating one value with inability to built a value hierarchy, a limited number of the levels of the value hierarchy. The indirect criterion was the duration of the structured interview as the measure of patient's and interviewer' s efforts. Cognitive dysfunction determined by the method of the structured interview was connected with the low score of the clock-drawing test. Compliance decline was noticed in the presence as well as in the absence of cognitive dysfunction. Determining values and their hierarchy may lead to the increase of patients compliance.

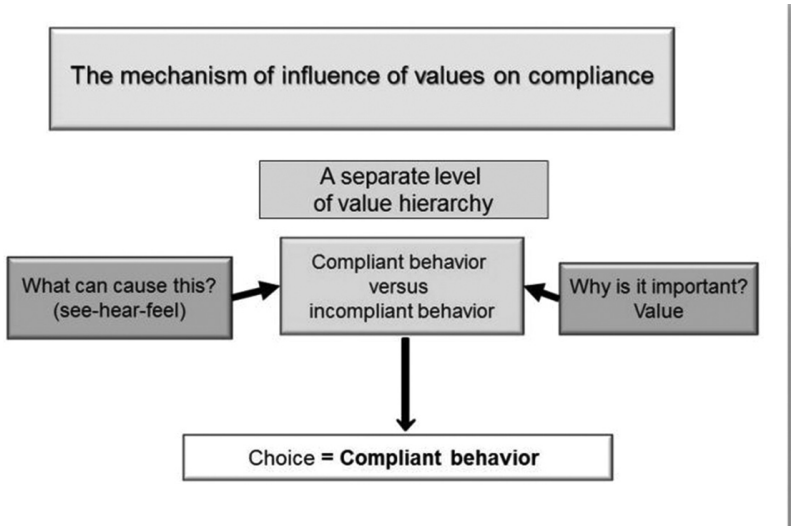

Conclusions: The method of the structured and algorithms interview with the assessment of the hierarchy of values is used to assess compliance and cognitive functions in patients with rheumatoid arthritis as well as to reveal the ways to increase compliance.

\section{REFERENCES:}

[1] Clin Rheumatol 2018 Jan 25. doi:10.1007/s10067-018-3990-9

[2] Luksha P, Tkachev A. Journal: Kybernetes, ISSN: 0368-492X, Year: 2007;36(7-8):956-971. doi:10.1108/03684920710777487

Disclosure of Interest: None declared

DOI: 10.1136/annrheumdis-2018-eular.4696

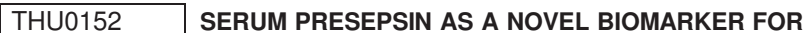 BACTERIAL INFECTION IN RHEUMATOID ARTHRITIS PATIENTS TREATED WITH TOCILIZUMAB}

E. Oguro $^{1}$, S. Tsuji ${ }^{1}$, K. Kuzuya ${ }^{1}$, Y. Okita ${ }^{1}$, H. Matsuoka ${ }^{1}$, S. Teshigawara ${ }^{1}$, M. Yoshimura ${ }^{1}$, Y. Harada ${ }^{1}$, M. Matsushita ${ }^{1}$, S. Ohshima ${ }^{2}$, J. Hashimoto ${ }^{1}$, Y. Saeki ${ }^{2} .{ }^{1}$ Department of Rheumatology and Allergology, ${ }^{2}$ Department of Clinical Research, NHO Osaka Minami Medical Center, Kawachinagano, Osaka, Japan

Background: Tocilizumab (TCZ), an inhibitor of interleukin-6 (IL-6), has been widely used to treat rheumatic diseases such as rheumatoid arthritis (RA) and juvenile idiopathic arthritis. Recently, TCZ was approved for use in patients with giant cell aortitis and Takayasu aortitis. However, TCZ treatment sometimes obscures changes in the conventional biomarkers for infection such as serum levels of C-reactive protein (CRP) and procalcitonin (PCT). Presepsin (P-SEP), a subtype of soluble CD14, has been recently identified as a biomarker for sepsis. In addition, we have reported the usefulness of P-SEP for the diagnosis of bacterial infection in RA patients because it is less affected by the disease activity.

Objectives: To examine the usefulness of P-SEP in RA patients complicated with bacterial infections during TCZ treatment.

Methods: In this study, 49 RA patients with bacterial infections (i+RA), 76 RA patients without bacterial infections (RA) and 23 healthy controls $(H C)$ were enrolled. The presence of infection was strictly diagnosed by bacteriological examinations, typical clinical characteristics such as fever $\left(38.0^{\circ} \mathrm{C}\right)$ and/or CRP elevation and/or increased white blood cell count, and improvements of these manifestations with antibiotics. Serum P-SEP levels were measured by an immunoassay. The CRP and PCT levels were measured simultaneously.

Results: The median serum P-SEP levels were 186.0 [interquartile range (IQR), 134.0-236.0], 691.0 [IQR, 345.5-842.0], 154.5 [IQR, 145.8-165.5] I, and 161.0 [IQR, 146.5-166.0] pg/mL for TCZ (n=25), i+TCZ (pre-antibacterial treatment; $n=7$ ), i+TCZ (post-antibacterial treatment; $n=7$ ) and the HC group, respectively. The P-SEP levels of the $\mathrm{i}+\mathrm{TCZ}$ group were significantly elevated compared with those of the TCZ group $(p<0.001)$. The $i+T C Z$ group displayed elevated P-SEP levels despite normal CRP and PCT levels. After antibacteria treatment, P-SEP levels of the $\mathrm{i}+\mathrm{TCZ}$ group were significantly decreased $(p=0.016)$.

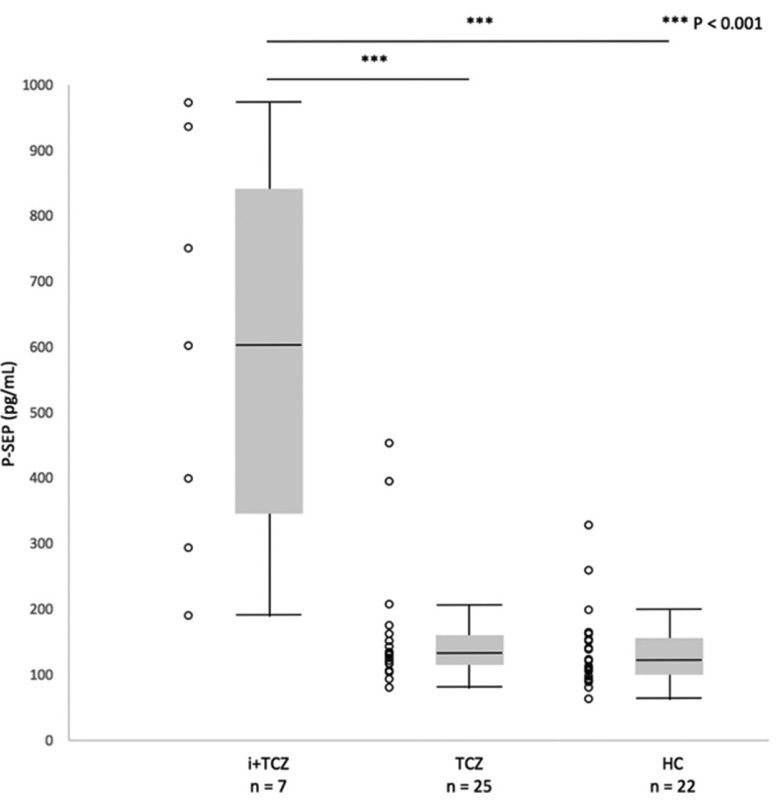

Conclusions: These results suggest that serum P-SEP levels are less affected by TCZ treatment compared with other conventional inflammatory biomarkers such as CRP and PCT. Moreover, P-SEP levels are useful for the assessment of bacterial infections in RA patients treated with TCZ

REFERENCE:

[1] Tsuji S, et al. Mod Rheumatol 2017;27(4):718-720.

Disclosure of Interest: None declared

DOI: 10.1136/annrheumdis-2018-eular.3914

THU0153
THE EFFECT OF 5-YEARS B-DMARDS TREATMENT ON
DIFFERENT 10-YEARS CARDIOVASCULAR RISK
SCORES APPLIED IN RHEUMATOID
ARTHRITISPATIENTS

F. Cacciapaglia, M. Fornaro, D. Renna, F. Cafarelli, G. Lopalco, M.G. Anelli,

C. Scioscia, G. Lapadula, F. Iannone. Rheumatology Unit; Department of

Emergency and Organs Transplantation (DETO), University of Bari, BARI, Italy

Background: Patients with rheumatoid arthritis (RA) have an excess risk of cardiovascular (CV) disease.

Objectives: We aimed to assess whether 5 years treatment with biologic DMARDs can impact on the 10 year $\mathrm{CV}$ risk assessed with different scores.

Methods: In this monocentric study we retrospectively evaluated data available at 2012 and 2017 to calculate the CV scores according to the Italian CV risk score Cuore project, ${ }^{1}$ QRISK2-2017 score ${ }^{2}$ and the score proposed by Solomon DH et al.. ${ }^{3}$ Moreover, RA characteristics were registered and correlated to the risk scores at baseline and after 60 months of treatment with RA approved biologic agents. Any CV event was registered.

Results: 110 patients with RA treated for the first time with a bDMARDs, and no prior CV events were included (mean age $52 \pm 11.3$ years; $80 \%$ women; median disease duration 36 months). During the evaluated period $47(42 \%)$ patients switched to a different bDMARD, 10 (9\%) patients stopped the treatment for side effects and $3(2.7 \%)$ patients with high CV risk scores at baseline presented a CV event within 4 years ( 2 myocardial infarction and 1 stroke). At baseline we observed a mean CV risk of 3.69 (95\% confidence interval [CI], 2.70-4.68) assessed as moderate by the Cuore project, $10.64(95 \% \mathrm{Cl} 8.48-12.8)$ and 10.43 (95\% CI 8.61-12.24) considered as high risk according to the QRISK2-2017 and Solomon's scores, respectively. After 5 years we recorded a significant increase in CV risk assessed by the Cuore project and the QRISK2-2017 score [4.20 (95\% $\mathrm{Cl} 3.23-5.18)$ and $13.12(95 \% \mathrm{Cl} 10,72-15,53)$, respectively; $\mathrm{p}<0.001$ vs 